УДК 621.311.001.63 (035)

\title{
МЕТОДИКА РАСЧЕТА И ВЫБОРА МЕСТА УСТАНОВКИ ПУНКТОВ РЕГУЛИРОВАНИЯ НАПРЯЖЕНИЯ В РАСПРЕДЕЛИТЕЛЬНЫХ ЭЛЕКТРИЧЕСКИХ СЕТЯХ 0,4-10(6) КВ
}

\section{Андрианова Людмила Прокопьевна \\ д-р техн. наук, профессор \\ Рябишина Лилия Амировна \\ канд. техн. наук, доцент \\ Хуртов Владислав Евгеньевич}

Уфимский государственный нефтяной технический университет

Аннотация. В статье приведено краткое описание вариантов применения и способов установки вольтдобавочных трансформаторов ВТД 0,4 кВ и пунктов регулирования напряжения ПРН 6-20 кВ в ЛЭП 0,4-6-10-20 кВ. Приведены методические рекомендации выбора места установки ВТД и ПРН в соответствии с требованиями нормативных документов. Приведены соотношения для определения потерь напряжения и мощности в ЛЭП. Представлен в табличной форме фрагмент расчета нормального режима участка ЛЭП при максимальных нагрузках, на основе которого выбрано оптимальное место установки ПРН, состоящей из трех ВТД, с номинальным током 200 А и диапазоном регулирования напряжения, равным $\pm 15 \%$.

Ключевые слова: вольтдобавочные трансформаторы, пункты регулирования напряжения, уставки регулирования, место установки, линия электропередачи, распределение напряжения. 


\title{
METHOD OF CALCULATION AND SELECTION OF THE INSTALLATION LOCATION OF VOLTAGE CONTROL POINTS IN DISTRIBUTION ELECTRIC NETWORKS 0,4-10 (6) KV
}

\section{Andrianova Lyudmila Prokopyevna Ryabishina Lilia Amirovna Hurtov Vladislav Evgenievich}

\begin{abstract}
The article provides a brief description of the application options and methods for installing additional voltage transformers VTD $0,4 \mathrm{kV}$ and voltage control points PRN 6-20 kV in power lines 0,4-6-10-20 Sq. The methodological recommendations for choosing the installation site of VTD and PRN in accordance with the requirements of regulatory documents are given. The relations for determining the voltage and power losses in power transmission lines are given. A fragment of the calculation of the normal mode of the power line section at maximum loads is presented in tabular form, on the basis of which the optimal location of the PRN installation, consisting of three VTD, with a rated current of $200 \mathrm{~A}$ and a voltage control range of $\pm 15 \%$, is selected.
\end{abstract}

Key words: surge transformers, voltage control points, control setpoints, installation location, power transmission line, voltage distribution.

Вольтодобавочные трансформаторы (ВДТ) и пункты регулирования напряжения (ПРН) применяют в распределительных сетях 0,4 - 6-20 кВ для [1]:

- повышения и стабилизации напряжения в сети;

- компенсации несимметрии фазных напряжений;

- оперативного реагирования на жалобы потребителей на качество электроэнергии;

- предотвращения повышения уровня напряжения у потребителей при обрыве нулевого провода или потере в его цепи контакта;

- снижения объема и срочности капиталовложений.

ВДТ устанавливается в разрыв линии электропередачи (ЛЭП) 0,4 кВ в трехфазной сети потребителей переменного тока напряжением 0,4 кВ частотой

50 Гц (рис.1, а). ВДТ устанавливается в ЛЭП только с односторонним питанием $[1,2]$. 


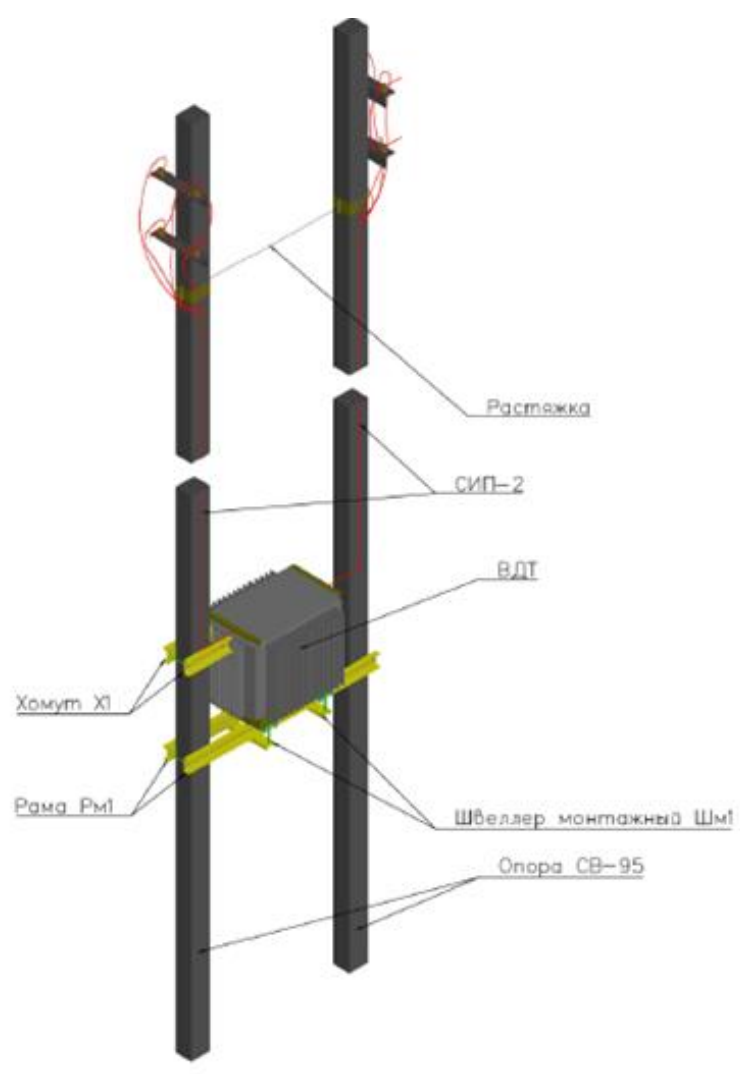

a)

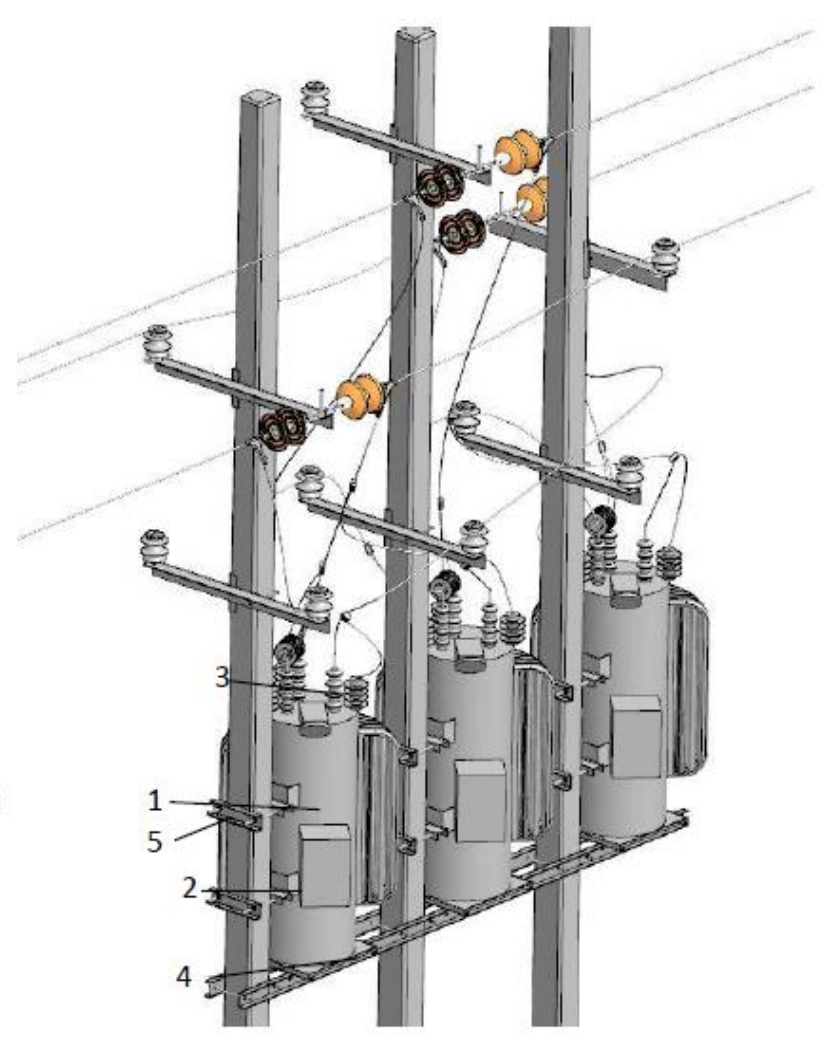

б)

\section{Рис.1. Общий вид и пример установки и ВДТ и ПРН $[1,2]$ :}

а - ВДТ 0,4 кВ, установленного на двух опорах;

б - ПРН 6-20 кВ, установленного на трех опорах:

1 - бак вольтодобавочного трансформатора (3 шт.);

2 - шкаф управления (3шт.);

3 - ограничители перенапряжения (12 шт.);

4 - опорные металлоконструкции (1 комплект);

5 - металлоконструкции крепления к опоре (6 комплектов)

ВДТ 6-20 кВ изготавливаются в однофазном исполнении. В трехфазной сети устанавливается группа из двух или из трех однофазных ВДТ, подключаемых по схеме «неполный треугольник» или «полный треугольник». Группа из двух или из трех однофазных ВДТ 6-20 кВ образует пункт ПРН с диапазоном регулирования напряжения: из двух ВДТ $\pm 10 \%$, из трех ВДТ \pm 15 \% [2]. Пример общего вида ПРН 6-20 кВ, установленного на трех опорах, представлен на рис. 1, б.

Место установки ВДТ и ПРН определяется расчетным или опытным методами, исходя из параметров ЛЭП. Расчетный метод установки ВДТ 
основывается на определении фактических потерь напряжения до потребителя в настоящий момент времени. На основании исходных данных производится расчет падения напряжения при максимальных нагрузках, а также с учетом роста нагрузок при подключении новых потребителей.

Опытный метод основывается на проведении измерений уровня напряжения в сети, по результатам которых определяется оптимальное место установки ВДТ для обеспечения соответствия показателей качества электрической энергии (ПКЭ) установленным требованиям, как для ближайших, так и для удаленных от трансформаторной подстанции (ТП) потребителей данной сети [2] .

После предварительного выбора места установки с учетом факторов, указанных в СТО [2] необходимо повторно провести расчет падения напряжения с учетом собственного сопротивления ПРН (таблица 1).

Таблица 1

Расчетные значения активного и реактивного сопротивления ПРН

\begin{tabular}{|l|c|c|c|c|}
\hline Тип & $\begin{array}{c}\text { Номинальный } \\
\text { ток, А }\end{array}$ & $\begin{array}{c}\text { Номинальное } \\
\text { напряжение, } \\
\text { кВ }\end{array}$ & $\begin{array}{c}\text { Активное } \\
\text { сопротивление } \\
r_{\Pi \text { Рн }} \\
\text { не более, Ом }\end{array}$ & $\begin{array}{c}\text { Реактивное } \\
\text { сопротивление } \\
x_{\Pi \text { бн }} \\
\text { не более, Ом }\end{array}$ \\
\hline ПРН-6(10)-100У1 & 100 & 6,10 & 0,25 & 0,8 \\
\hline ПРН-6(10)-150 У1 & 150 & 6,10 & 0,16 & 0,7 \\
\hline ПРН-6(10)-200 У1 & 200 & 6,10 & 0,12 & 0,4 \\
\hline ПРН-6(10)-300У1 & 300 & 6,10 & 0,09 & 0,3 \\
\hline ПРН-6(10)-400 У1 & 400 & 6,10 & 0,07 & 0,12 \\
\hline ПРН-6(10)-500У1 & 500 & 6,10 & 0,04 & 0,1 \\
\hline
\end{tabular}

Для схемы «Питание РП (РТП) 10(6) кВ от двух линий» необходимо рассчитать нормальный и послеаварийный режим для варианта отключения каждой из линий (рис. 2). 


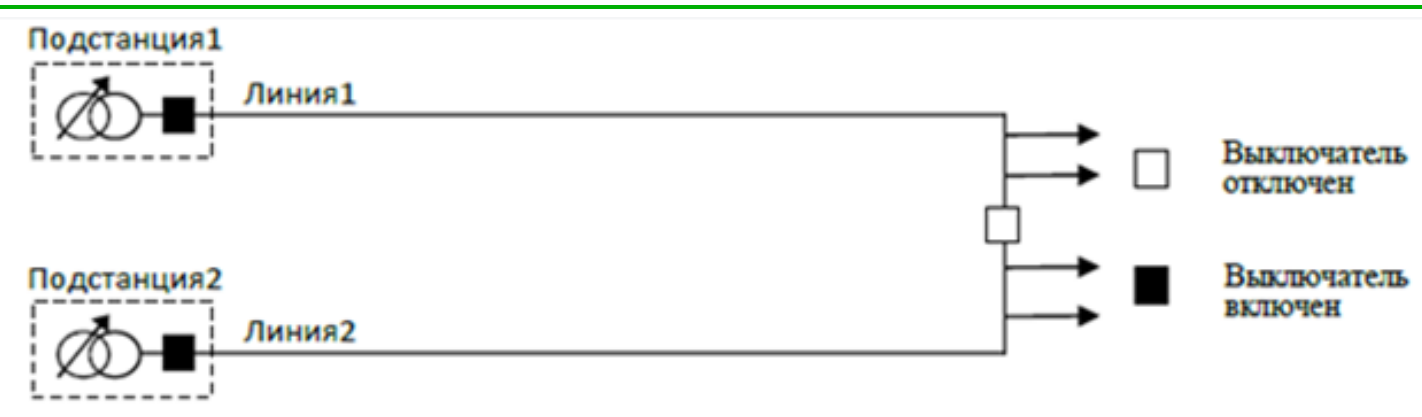

a

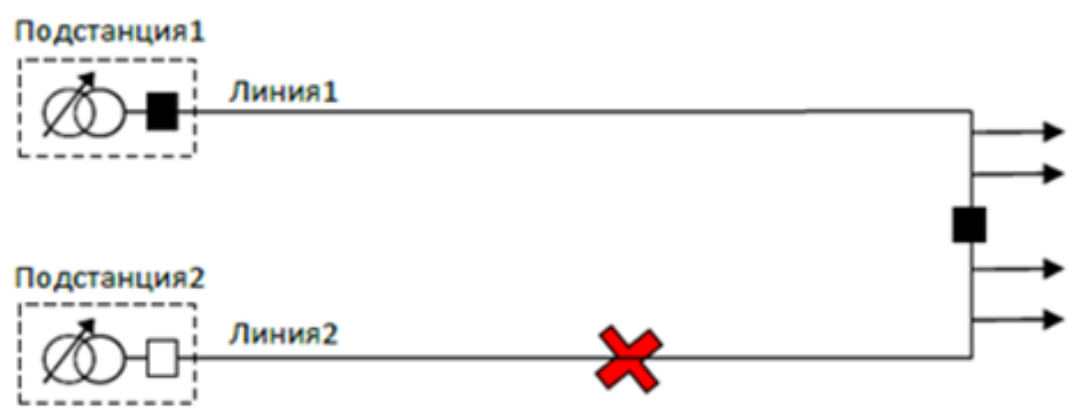

Вықтючатель откточен

б

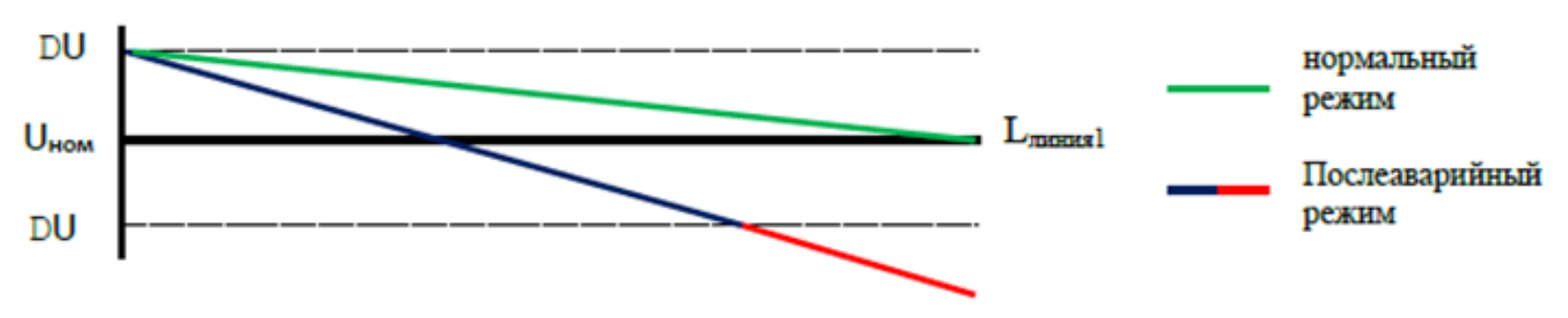

B

Рис. 2. Схема питания РП (РТП) 6-20 кВ от двух линий [2]:

а - нормальный режим; б - послеаварийный режим;

в - распределение напряжения на ЛЭП в нормальном и послеаварийном режимах

График падения напряжения строится от начала линии до точки с минимальным уровнем напряжения. На основании графика выбор места установки осуществляется таким образом, чтобы при максимальном диапазоне регулирования 10 или 15\%, выходное напряжения ПРН не превышало допустимое для потребителей, находящихся за ПРН (рис. 3). 

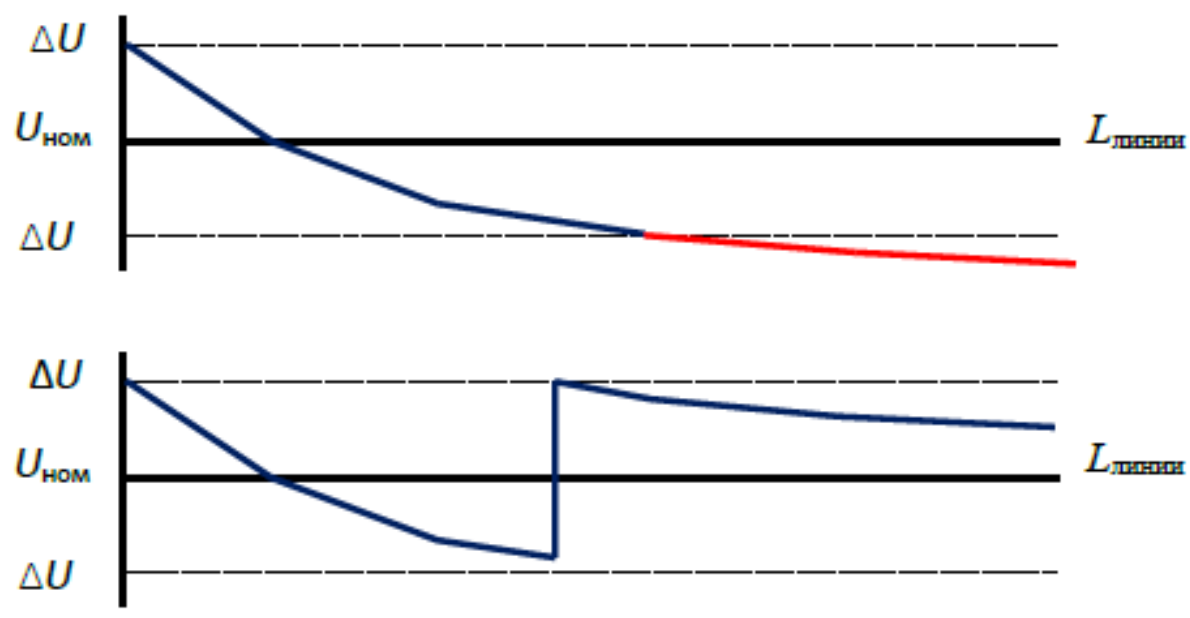

Рис. 3. Эпюра распределения напряжения на ЛЭП [2]

Если установленный ПРН не обеспечивает нормальный уровень напряжения до конца линии, необходимо ставить еще один ПРН для регулирования напряжения в каскаде. Номинальный ток ПРН должен превышать расчетный ток в месте установки не менее чем на $20 \%$.

Расчет напряжений проводится для самого длинного участка линии. Потребляемая мощность в узлах рассчитывался исходя из значения максимального тока в начале линии и установленных мощностей ТП потребителей. Для каждой ТП потребляемая мощность определяется пропорционально отношению максимальной мощности в начале линии, исходя их значения тока, и суммарной мощностью всех ТП.

Расчет падения напряжения, кB, на участке проводится по формуле

$$
U_{2}=U_{1}-\frac{P_{1} \cdot R+Q_{1} \cdot X}{U_{1}} \cdot 0,001,
$$

где $U_{1}$ - напряжение в начале участка, кВ ;

$P_{1}$ - активная мощность в начале участка, кВт,

$$
P_{1}=P_{2}+\Delta P_{12}
$$

где $P_{2}$ - активная мощность в конце участка, кВт;

$\Delta P_{12}$ - потери активной мощности на участке, кВт;

$Q_{1}$ - реактивная мощность в начале участка, квар,

$$
Q_{1}=Q_{2}+\Delta Q_{12},
$$

где $Q_{2}$ - реактивная мощность в конце участка, квар;

$\Delta Q_{12}$ - потери реактивной мощности на участке, квар;

$R$ - активное сопротивление ВЛ на участке, Ом;

$X$ - реактивное сопротивление ВЛ на участке, Ом. 
Потери активной мощности рассчитываются по формуле

$$
\Delta P=\frac{P_{1}^{2}+Q_{1}^{2}}{U_{1}^{2}} \cdot R .
$$

Потери реактивной мощности рассчитываются по формуле

$$
\Delta Q=\frac{P_{1}^{2}+Q_{1}^{2}}{U_{1}^{2}} \cdot X .
$$

В качестве примера на рис. 4 приведена расчетная схема ЛЭП с ПРН, полученная на основе расчета напряжения для сети с исходными данными:

- однолинейная схема ЛЭП 10 кВ;

- напряжение в начале узла - 10,5 кВ;

- коэффициент мощности - 0,99 (коммунально-бытовая нагрузка);

- максимальный ток в начале линии - 129 А.

Удельные активные сопротивления проводов указаны в таблице 2.

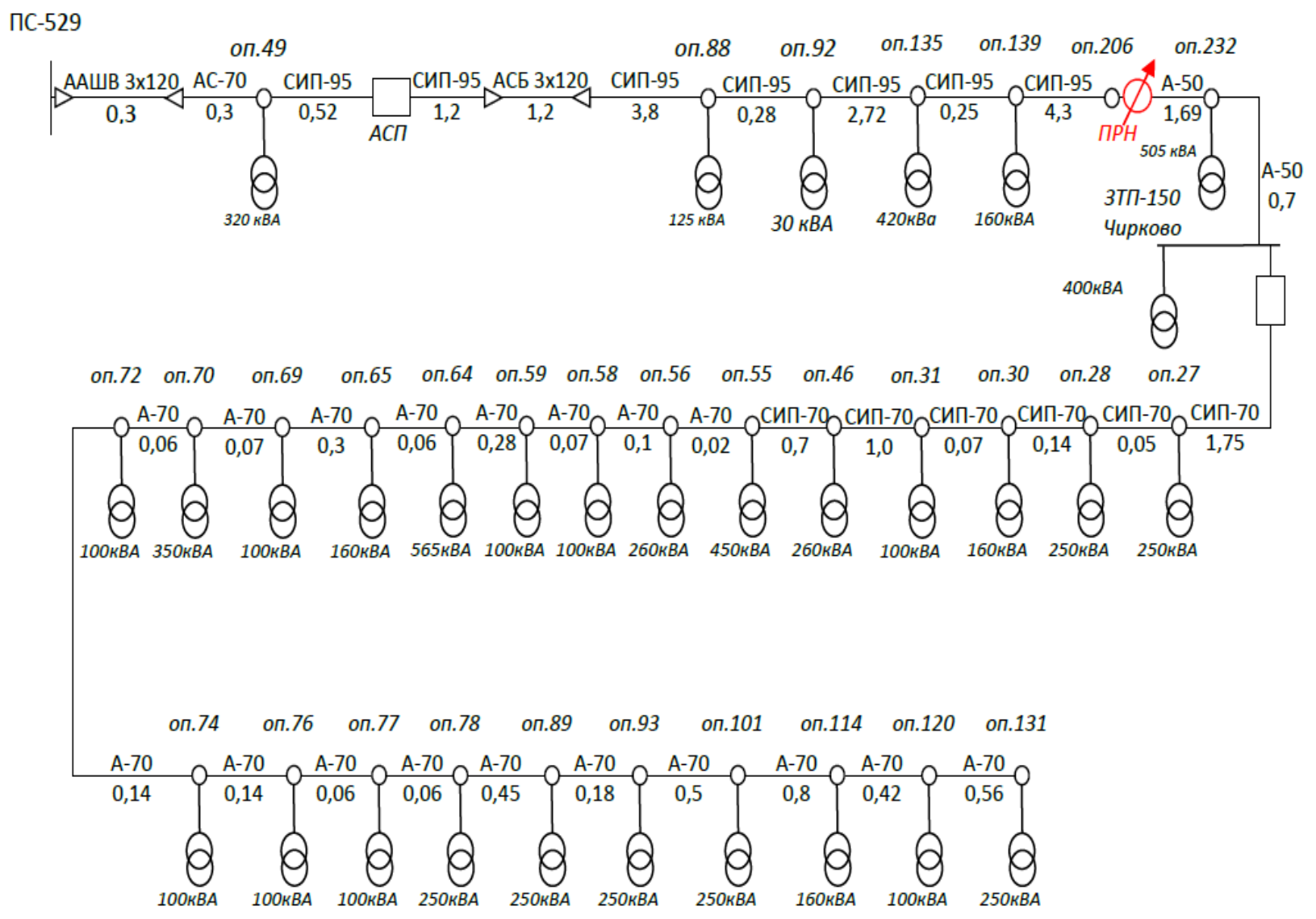

\section{Рис. 4. Расчетная схема ЛЭП с установкой ПРН между опорами 206-232}




\section{Таблица 2}

Параметры ВЛ 6-10 кВ с проводами марок СИП и А

\begin{tabular}{|l|c|c|}
\hline Марка провода & $\begin{array}{c}\text { Активное сопротивление } \\
\mathrm{R}_{\mathrm{o}}, \text { Ом } / \text { км }\end{array}$ & $\begin{array}{c}\text { Реактивное сопротивление } \\
\mathrm{X}_{\mathrm{o}}, \text { Ом / км }\end{array}$ \\
\hline СИП-70 & 0,49 & 0,3 \\
\hline СИП-95 & 0,36 & 0,3 \\
\hline А-50 & 0,6 & 0,35 \\
\hline А-70 & 0,42 & 0,35 \\
\hline ААШВ3х120 & 0,26 & 0 \\
\hline АСБ3х240 & 0,13 & 0 \\
\hline
\end{tabular}

В таблице 3 приведен фрагмент расчета нормального режима ЛЭП при максимальных нагрузках.

Из результатов расчета, приведенных в таблице 3, максимальное отклонение напряжения составляет на опоре $232(10,5-8,6)=1,9$ кВ или $18 \%$ от номинального значения, что превышает допустимые отклонения напряжения. Для обеспечения допустимого значения уровня напряжения рекомендуется установка ПРН с вольтодобавочными автотрансформаторами 200A с диапазоном регулирования $\pm 15 \%$. Напряжение в районе опоры 139 составляет 9,3 кВ. При установке ПРН напряжение будет составлять 10,8 кВ, следовательно установку ПРН целесообразно произвести ближе к опоре 206.

Таблица 3

Расчет нормального режима ЛЭП при максимальных нагрузках

\begin{tabular}{|c|c|c|c|c|c|c|}
\hline Узел (опора) & $\begin{array}{c}\text { Марка } \\
\text { провода }\end{array}$ & $\begin{array}{c}\text { Расстояние от } \\
\text { ЦП, км }\end{array}$ & $\begin{array}{c}L_{\text {участка, }} \\
\text { км }\end{array}$ & $\begin{array}{c}R \text { вл, } \\
\text { Ом }\end{array}$ & $\begin{array}{c}X_{\text {Вл, }} \\
\text { Ом }\end{array}$ & $\begin{array}{c}S \text { тп, } \\
\text { кВ·А }\end{array}$ \\
\hline 1 & 2 & 3 & 4 & 5 & 6 & 7 \\
\hline ПС 529 & - & 0,0 & - & - & - & - \\
\hline $49 \mathrm{a}$ & $\begin{array}{c}\text { ААШВ } \\
\text { 3х120+АС-70 }\end{array}$ & 3,4 & 3,4 & 1,38 & 1,09 & 320 \\
\hline 88 & $\begin{array}{c}\text { СИП- } \\
\text { 95+АСБ3х240 }\end{array}$ & 10,2 & 6,7 & 2,16 & 1,66 & 125 \\
\hline 92 & СИП-95 & 10,4 & 0,3 & 0,10 & 0,08 & 30 \\
\hline 135 & СИП-95 & 13,2 & 2,7 & 0,99 & 0,82 & 420 \\
\hline 139 & СИП-95 & 13,4 & 0,3 & 0,09 & 0,08 & 160 \\
\hline 206 & СИП-95 & 17,7 & 4,3 & 1,56 & 1,29 & 0 \\
\hline 232 & А-50 & 19,7 & 2,0 & 1,18 & 0.69 & 505 \\
\hline
\end{tabular}




\begin{tabular}{|c|c|c|c|c|c|c|c|c|}
\hline \multirow{2}{*}{ Узел (опора) } & $\begin{array}{c}\text { Нагрузки в } \\
\text { узлах, } \\
\text { кВт }\end{array}$ & \multicolumn{3}{|c|}{$\begin{array}{c}\text { Нагрузки в начале } \\
\text { узлов, кВт }\end{array}$} & \multicolumn{2}{c|}{$\begin{array}{c}\text { Потери в } \\
\text { участках, } \\
\text { кВт }\end{array}$} & $U$, кВ & $I, \mathrm{~A}$ \\
\hline $1 \ldots$ & 8 & 9 & 10 & 11 & 12 & 13 & 14 & 15 \\
\hline & $P$ & $Q$ & $P$ & $Q$ & $\Delta P$ & $\Delta Q$ & 10,5 & - \\
\hline ПС 529 & 88,7 & 12,6 & 2323 & 569,5 & 71,8 & 56,5 & 10,1 & 129 \\
\hline $49 \mathrm{a}$ & 34,7 & 4,9 & 2162 & 500,4 & 103 & $19, \mathrm{~A}$ & 9,6 & 124 \\
\hline 88 & 8,3 & 1,2 & 2024 & 416,0 & 4,7 & 3,9 & 9,6 & 123 \\
\hline 92 & 116,4 & 16,6 & 2011 & 411,0 & 45,4 & 37,6 & 9,3 & 123 \\
\hline 135 & 44,4 & 6,3 & 1849 & 356,8 & 3,7 & 3,1 & 9,3 & 116 \\
\hline 139 & 0,0 & 0,0 & 1801 & 347,4 & 60,7 & 50,1 & 9,0 & 113 \\
\hline 206 & 140,0 & 19,9 & 1741 & 297,3 & 42,4 & 24,7 & 8,7 & 109 \\
\hline 232 & 110,9 & 15,8 & 1558 & 252,6 & 13,8 & 8,1 & 8,6 & 104 \\
\hline
\end{tabular}

C учетом условий возможности подъезда техники для монтажа оборудования оптимальное место установки ПРН выбрано в пролете между опорами 207 и 208 (см. рис. 4).

Результаты расчета падения напряжения с учетом увеличения нагрузок на 20\% в графическом виде представлены на рис. 5.

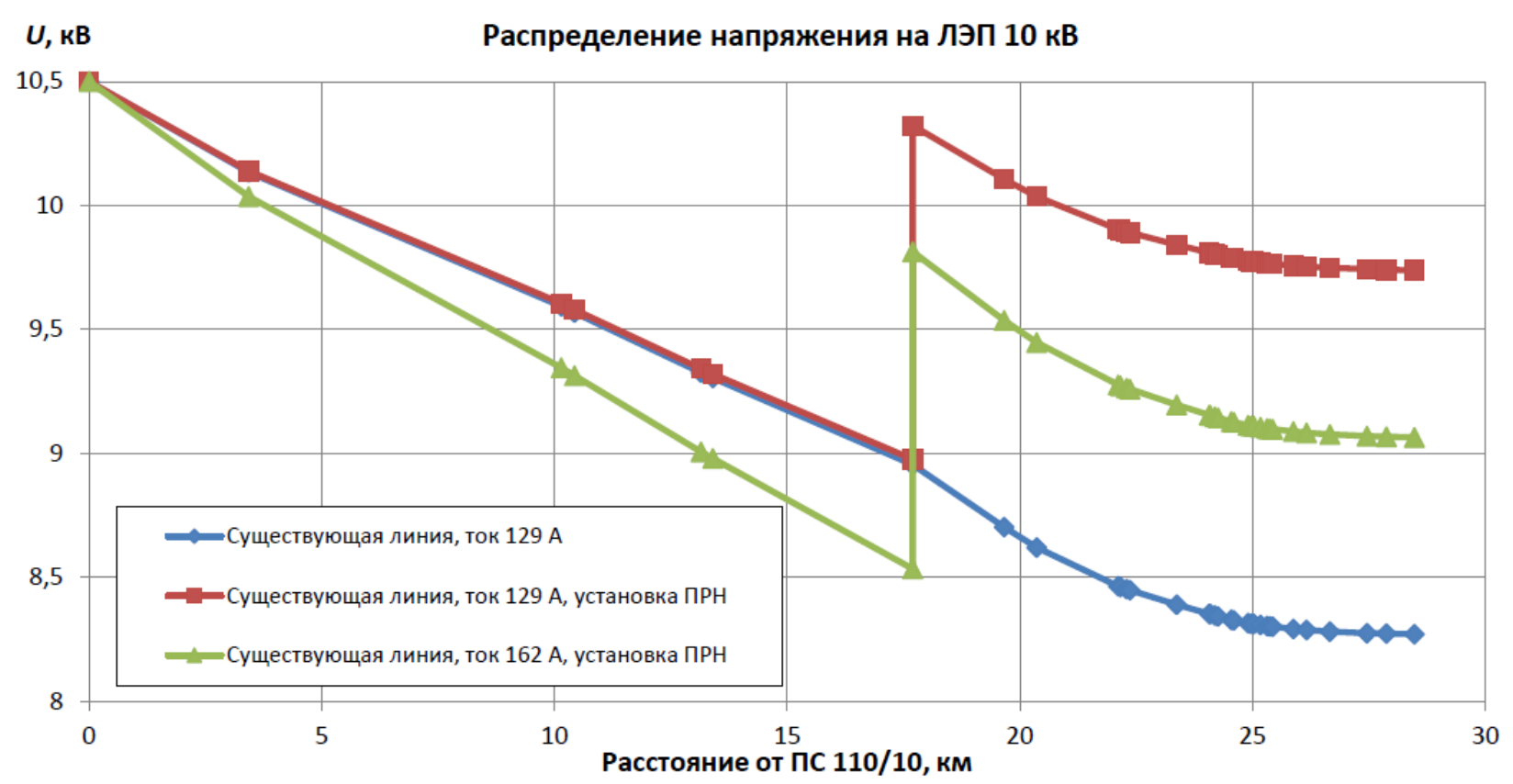

\section{Рис. 5. Распределение напряжения в ЛЭП 10 кВ с учетом увеличения нагрузок на $20 \%$ [2]}


Настройки ПРН позволяют обеспечивать поддержание постоянного напряжения $10,3 \pm 0,2$ кВ в районе опоры 232. C учетом диапазона чувствительности напряжения не будет превышать 10,5 кВ.

Принятые уставки параметров регулирования:

- установленное напряжение, 10,3 кВ (первичное);

- диапазон чувствительности регулирования, $\pm 0,2$ кВ (первичное);

- выдержка времени, 30 с.

Вывод: установка ПРН 10 кВ 200 А с диапазоном регулирования $\pm 15 \%$ обеспечивает нормальный уровень напряжения по всей длине ЛЭП, как при существующих максимальных нагрузках, так и при увеличении нагрузок на $20 \%$.

\section{Список литературы}

1. Вольтодобавочные трансформаторы. Общие технические требования : СТО 34.01-3.2-013-2017. Стандарт организации ПАО «Россети», введ. 02.08.2017. - 43 c. // www.rosseti.ru. - Режим доступа 12.03.2021.

2. Методические указания по применению вольтодобавочных трансформаторов (пунктов регулирования напряжения) 6-20 кВ и вольтодобавочных трансформаторов 0,4 кВ распределительных сетей. Том 1.1. Методические указания : СТО 34.01-3.2.17014.1-2020. Стандарт организации ПАО «Россети», введ. 04.03.2020. - 44c // www.rosseti.ru. - Режим доступа 12.03.2021.

3. Методические указания по применению вольтодобавочных трансформаторов (пунктов регулирования напряжения) 6-20 КВ и вольтодобавочных трансформаторов 0,4 КВ в линиях электропередачи распределительных сетей. Том 1.2. Типовые решения : СТО 34.01-3.2.17-014.22020. Стандарт организации ПАО «Россети», введ. 04.03.2020. - 44c. // www.rosseti.ru. - Режим доступа 12.03.2021.

(с) Л.П. Андрианова, Л.А.Рябишина, В.Е. Хуртов, 2021 